Gerard F. Lapiña, MD

Samantha S. Castañeda, MD

Department of Otorhinolaryngology Head and Neck Surgery

Rizal Medical Center
Correspondence: Dr. Samantha S. Castañeda

Department of Otorhinolaryngology

Head and Neck Surgery

Rizal Medical Center

Barangay Pineda, Shaw Boulevard, Pasig City 1600

Philippines

Phone: (632) 8658400 local 197

Email:ent.hns_rmc@yahoo.com

The authors declared that this represents original material that is not being considered for publication or has not been published or accepted for publication elsewhere, in full or in part, in print or electronic media; that the manuscript has been read and approved by all the authors, that the requirements for authorship have been met by each author, and that each author believes that the manuscript represents honest work.

Disclosures: The authors signed disclosures that there are no financial or other (including personal) relationships, intellectual passion, political or religious beliefs, and institutional affiliations that might lead to a conflict of interest.

Presented at the Philippine Society of Otolaryngology Head and Neck Surgery Descriptive Research Contest (1st Place), October 6, 2016. Natrapharm, The Patriot Bldg. Parañaque City.

\section{Diagnostic-to-Treatment Interval and Disease Progression among Head and Neck Cancer Patients Undergoing Surgery}

\begin{abstract}
Objective: To determine whether the interval from pathological diagnosis to treatment is significantly delayed, and the presence or absence of disease progression occurring in those with, and without treatment delay, among head and neck cancer patients in our institution.
\end{abstract}

\section{Methods:}

\section{Design: $\quad$ Retrospective Chart Review \\ Setting: $\quad$ Tertiary Government Hospital}

Participants: Medical records of 70 patients with newly diagnosed head and neck cancer who underwent primary surgery from January 2011 to December 2015 were retrieved and available data were extracted.

Results: A total of 28 patients were included in this study. Majority of the cancers were in the larynx (42.9\%) and oral cavity (42.9\%). The mean diagnostic-to-treatment interval (DTI) was 54 days but $5(17.8 \%)$ out of the 28 had a DTI of more than 60 days. Four (80\%) with a DTI more than 60 days had an upstage during surgery while $4(17.4 \%)$ patients with DTI less than or equal to 60 days also had an upstage. $2(60 \%)$ patients with treatment delay had tumor progression compared to 5 (21.7\%) of those without treatment delay. Only $1(20 \%)$ out of the 5 patients with treatment delay had increased nodal metastasis in contrast to 8 (34.8\%) of those who did not have treatment delay.

Conclusion: A number of patients undergoing surgery in our institution experienced delay to initiate treatment of more than 60 days and majority of these patients were noted to have disease progression. However, even patients with treatment prior to 60 days had increases in tumor stage, which may suggest that the interval aimed for should be shorter than 60 days.

\section{Keywords: head and neck cancer, treatment delay, diagnostic interval, tumor progression}

Neoplasms, including head and neck cancers, are the third leading of cause of mortality in the Philippines. ${ }^{1}$ Establishing diagnoses at an earlier stage and early initiation of treatment are essential to achieve good treatment outcome. ${ }^{2}$ Diagnostic-to-treatment interval (DTI) is defined as the interval from which histopathological diagnosis is established until radiotherapy or chemotherapy is commenced or the actual date of surgery. ${ }^{2,3}$ Various factors can cause delay or prolonged DTI in the management of patients with head and neck cancer and should be avoided if possible. ${ }^{4}$ A significant delay that confers a detrimental effect on survival is defined as more 


\section{ORIGINAL ARTICLES}

than 60 days from the pathological diagnosis to commencement of treatment. ${ }^{5}$ In our institution, despite priority given to head and neck cancer patients, there are still patients who worsen from the time they are diagnosed to the actual day of the surgery. This study aimed to determine whether there is treatment delay in head and neck cancer patients operated on in our institution and to determine if there is progression in stage, tumor size and lymph node status occurring in these patients.

\section{METHODS}

With Ethical Review Board approval, records of all 70 patients with newly diagnosed head and neck cancers that underwent surgery in Rizal Medical Center from January 2011 to December 2015 were identified, and retrieved to extract patient and tumor characteristics such as age, sex, primary site of cancer, date of pathological diagnosis and exact date of surgery. Corresponding TNM Staging, based on the American Joint Committee on Cancer Staging in 2010 ( $7^{\text {th }}$ edition) ${ }^{6}$ during the time of diagnosis and eventual surgery were also noted. Excluded were patients with thyroid neoplasms (due to their relatively better prognosis compared to other head and neck cancers), those with incomplete records or who were admitted for surgery of tumor recurrence. Patients with unresectable tumors and those with metastasis during the time of diagnosis were also not included in this study. The patients were divided into two groups based on DTI of $\leq 60$ days and $>60$ days. Data were tabulated in Microsoft Excel 2016 (v16.0.6769.2017, Microsoft Corp., Redmond, WA, USA) and descriptive statistics were computed.

\section{RESULTS}

A total of 31 out of 70 patient records were initially considered for inclusion, with one more excluded due to inadequate data, and two more excluded because they underwent surgery for recurrence, leaving a total of 28 patient records included. The ages of the patients ranged from $26-72$ years (mean, 56.9 years), with $46.4 \%$ more than 60 years of age and $67.9 \%$ were male. The DTI ranged from 10 to 363 days with a

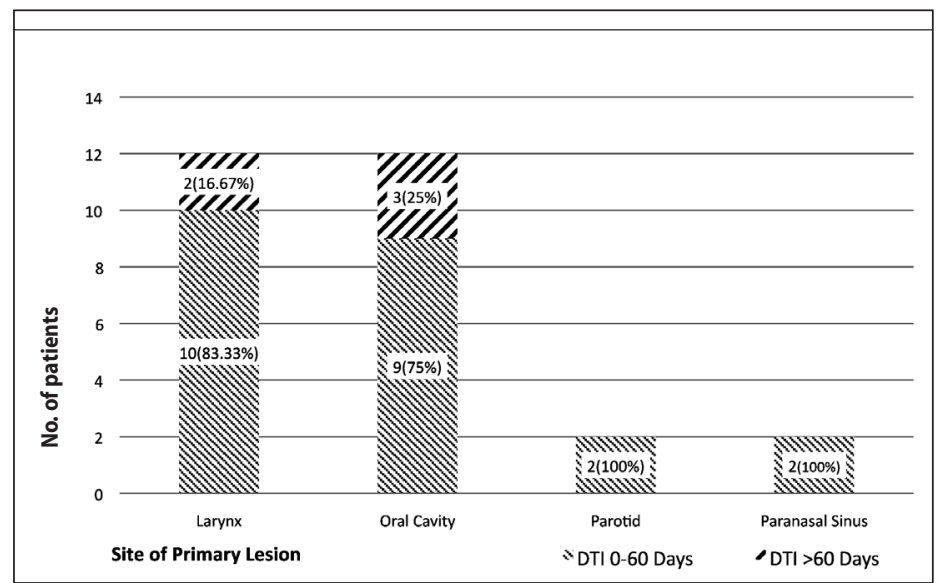

Figure 1. Diagnostic-to-Treatment Interval and Site of Primary Lesion median of 54 days. Out of the 28 patients, $5(17.9 \%)$ had a significant delay in the initiation of treatment.

The most common primary sites were the larynx (42.9\%) and oral cavity (42.9\%). Treatment delay (DTI $>60$ days) was present in $16.67 \%$ of patients with laryngeal malignancy in compared to $25 \%$ of patients with oral cavity malignancy as shown in Figure 1. A minority of patients (14.29\%) were diagnosed with malignancies of the parotid and paranasal sinus. No treatment delay was noted in these patients.

The majority (75\%) of patients were diagnosed at a late stage (stage III and IV) with a smaller portion (25\%) diagnosed at an earlier stage (Stage I and II). Across all the stages, there were patients who experienced treatment delay (13.33 - 33.33\%). (Figure 2)

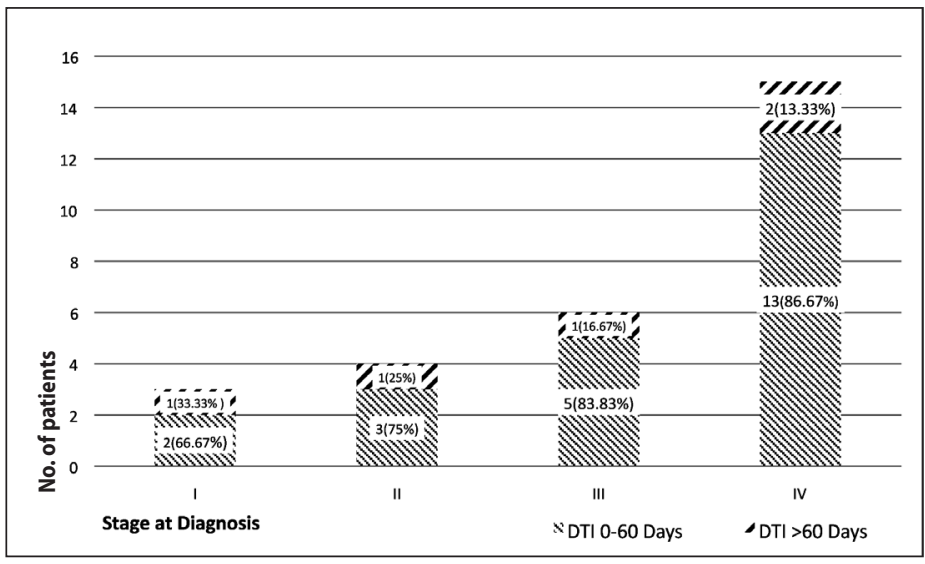

Figure 2. Diagnostic-to-Treatment Interval and Stage at Diagnosis *Stage at diagnosis based on the 2010 AJCC TNM Staging

Figure 3 shows that 4 out of 5 patients (80\%) with treatment delay had an increased stage at the time of diagnosis either due to increased tumor size, increased nodal metastases or both. Despite having been operated on within 60 days from the time of pathological diagnosis, there were still 4 out of 23 patients (17.4\%) that had increased stage at the time of surgery.

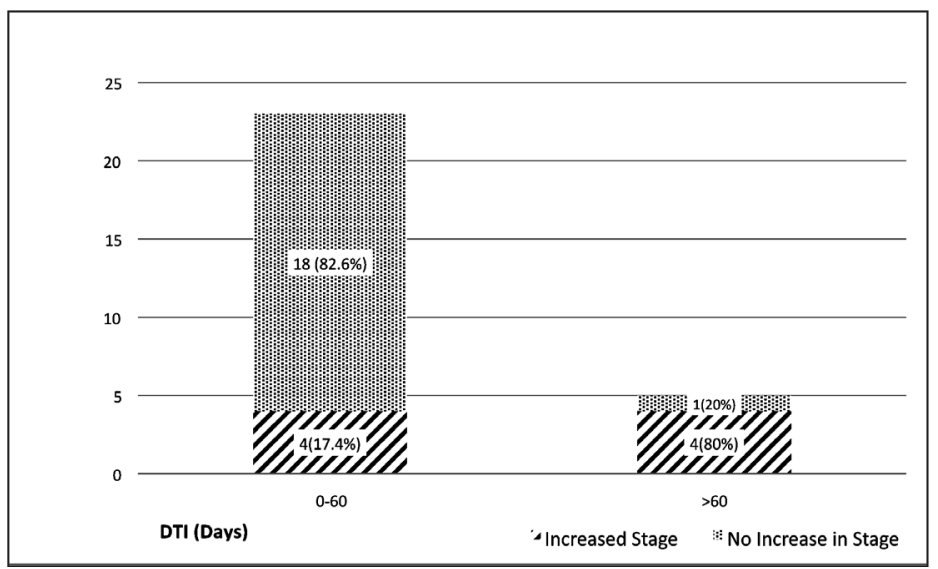

Figure 3. Diagnostic-to-Treatment Interval and TNM Staging *Stage according to the 2010 AJCC TNM Staging 
ORIGINAL ARTICLES

\section{Tumor Stage}

Increase in tumor stage was noted in $3(60 \%)$ of 5 patients with treatment delay, compared to $5(21.7 \%)$ of 23 patients without treatment delay as shown in Figure 4. Among the patients who were operated on or before 60 days, there were still patients who experienced marked tumor growth as documented by an increase in tumor stage. The shortest interval observed in which there was tumor upstage was 25 days.

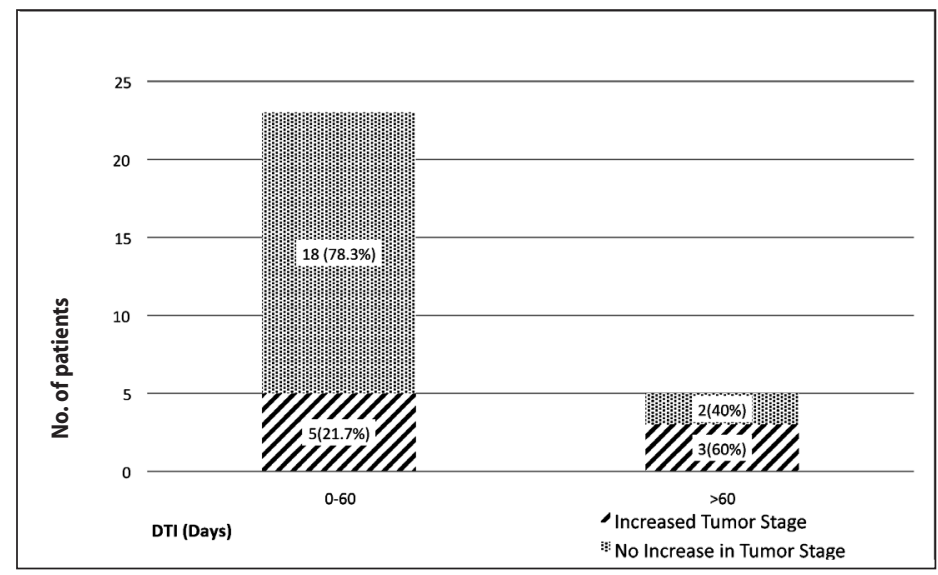

Figure 4. Diagnostic-to-Treatment Interval and Tumor Stage *Tumor Stage according to the 2010 AJCC TNM Staging

\section{Nodal Metastases}

Increase in nodal metastasis was observed in $8(34.8 \%)$ of 23 patients without treatment delay and only $1(20 \%)$ of the 5 patients with treatment delay. (Figure 5) Increased nodal stage was observed in as early as 12 days from the time of histopathological diagnosis. There was one patient with laryngeal squamous cell carcinoma initially diagnosed as N2c but the final histopathologic diagnosis was N2b.

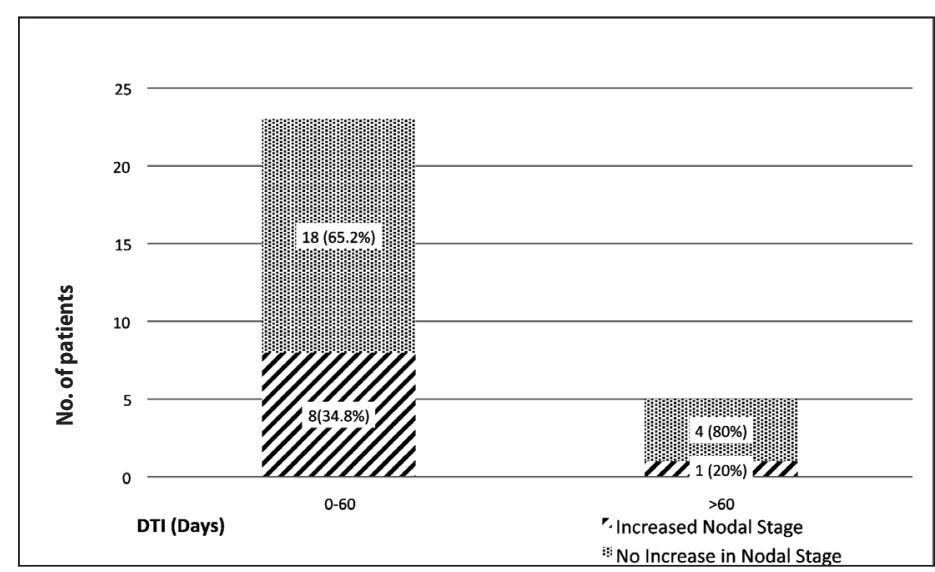

Figure 5. Diagnostic-to-Treatment Interval and Nodal Stage *Nodal Stage according to the 2010 AJCC TNM Staging

\section{DISCUSSION}

This study aimed to determine if there was treatment delay and the presence or absence of disease progression in patients undergoing surgery for head and neck cancer. The authors found out that the median DTI for head and neck cancers in our institution was 54 days. This interval is subpar compared to the findings of Lynhe et al. of decreasing median DTIs of 47 days in 1992, 31 days in 2002 and 25 days in 2010 among different institutions in Denmark, mandated by government to initiate treatment without delay in head and neck cancer patients. Another study with a shorter median DTI of 48 days found out on subgroup analysis, that the median DTI of patients with late stage head and neck cancer in their institution was significantly prolonged at 57 days, ${ }^{2}$ similar to our study.

Even though the median time in our institution did not exceed 60 days, this is still unfavorable, according to the findings of Murphy et al. "a DTI of at least 46 days seemed to affect survival, and a DTI of more than 60 days persistently had a detrimental effect on survival." 5 The Dutch guidelines also proposed that the interval from initial consult to treatment should not be more than 30 days because tumor doubling times of 30 days or less in some of these cancers implies progression of disease. ${ }^{10}$ However, this is difficult to achieve in our setting where a lot of factors, professional and patient-related, possibly result in prolonged DTI. Studies have shown that doubling time of tumors occur at an average 87-96 days and or as brief as 30 days for fast growing tumors. ${ }^{10,11}$ This concept is essential since we could expect to see tumor progression at a similar rate in our study in which the shortest interval was 25 days.

We found out that even in patients without treatment delay, $34.8 \%$ had an increase in lymph node metastases which translates to poorer outcomes since this is included in the independent factors that affect survival rate negatively. ${ }^{9}$ The presence of nodal metastases in the neck has been said to decrease 5 -year survival by $50 \%$ and increase the risk for metastasis two-fold. ${ }^{13}$ Similarly, another study also concluded that an increasing number nodes positive for malignant cells confers a worse outcome for these patients. ${ }^{14}$ Interestingly, one of the patients had clinically positive nodes bilaterally and only those on the ipsilateral side turned out positive for malignant cells resulting in a lower nodal stage. This could be explained by the study of Finn et al. in 2002 which concluded that not all clinically positive and suspicious nodes would turn out to have invasion with malignant cells and that $30 \%$ of clinically positive nodes are falsely positive., ${ }^{9,15}$

Specific causes for delay were not identified due to the limited data available on the retrieved charts as to why the DTI was prolonged in some patients. Another limitation is that patients who underwent nonsurgical management were not included in this study. Patients who were initially candidates for surgery and rendered non-operable due to disease progression not identified since this study only encompassed 
those who underwent surgery. We recommend that a prospective study be done which would include all patients diagnosed with head and neck cancer, both surgically and non-surgically managed patients, wherein close monitoring and documentation is done from initial consult up until any form of therapeutic intervention is done. In this way, specific and significant causes of delay may be identified and analyzed to recommend preventive measures and expedite health care for these patients.

In conclusion, a number of patients undergoing surgery in our institution experience treatment delay. There was also disease progression, in terms of increase in size of the primary tumor or increased nodal metastases, noted in majority of these patients.

REFERENCES

1. Department of Health [Internet] Philippines: Statistics; c2016 [updated 2013 April 26; cited 2016 Aug 1]. Leading Causes of Mortality. Available from: http://portal.doh.gov.ph/node/198.html.

2. Patel UE, Brennan TE. Disparities in head and neck cancer: assessing delay in treatment initiation Laryngoscope. 2012 Aug;122(8):1756-60. DOI: 10.1002/lary.23357; PMID: 22570084.

3. Stoker SD, Wildeman MA, Fles R, Indrasari SR, Herdini C, Wildeman PL, et al. A prospective study: current problems in radiotherapy for nasopharyngeal carcinoma in Yogyakarta, Indonesia. PLoS One. 2014 Jan 23;9(1): e85959. DOI: 10.1371/journal.pone.0085959; PMID: 24465811; PMCID: PMC3900459.

4. Nash R, Hughes J, Sandison A, Stewart S, Clarke P, Mace A. Factors associated with delays in head and neck cancer treatment: case-control study. J Laryngol Otol. 2015 Apr;129(4):383-5. DOI: 10.1017/S0022215115000687; PMID: 25788249.

5. Murphy CT, Galloway TJ, Handorf EA, Egleston BL, Wang LS, Mehra R, et al. Survival impact of increasing time to treatment initiation for patients with head and neck cancer in the United States. J Clin Oncol. 2016 Jan 10;34(2):169-78. DOI: 10.1200/JCO.2015.61.5906; PMID: 26628469; PMCID: PMC4858932.

6. Edge SB, Byrd DR, Compton CC, Fritz AG, Greene FL, Trotti A. Seventh Edition of AJCC Cancer Staging Manual. Springer-Verlag, New York, NY. 2010.

7. Lyhne NM, Christensen A, Alanin MC, Bruun MT, Jung TH, Bruhn MA, et al. Waiting times for diagnosis and treatment of head and neck cancer in Denmark in 2010 compared to 1992 and 2002. Eur J Cancer. 2013 May;49(7):1627-33. DOI: 10.1016/j.ejca.2012.11.034; PMID: 23274198.

8. Hörmann $\mathrm{K}$, Sadick $\mathrm{H}$. Role of surgery in the management of head and neck cancer: contemporary view of the data in the era of organ preservation. J Laryngol Otol. 2013 Feb;127(2):121-7. DOI: 10.1017/S0022215112002988; PMID: 23298649.

9. Tong XJ, Shan ZF, Tang ZG, Guo XC. The impact of clinical prognostic factors on the survival of patients with oral squamous cell carcinoma. J Oral Maxillofac Surg. 2014 Dec;72(12):2497.e1-10. DOI: 10.1016/j.joms.2014.07.001; PMID: 25454713.

10.van Harten MC, de Ridder M, Hamming-Vrieze O, Smeele LE, Balm AJ, van den Brekel MW. The association of treatment delay and prognosis in head and neck squamous cell carcinoma (HNSCC) patients in a Dutch comprehensive cancer center. Oral Oncol. 2014 Apr;50(4):282-90. DOI: 10.1016/j.oraloncology.2013.12.018; PMID: 24405882.

11.Waaijer A, Terhaard CH, Dehnad H, Hordijk GJ, van Leeuwen MS, Raaymakesr CP, et al. Waiting times for radiotherapy: consequences of volume increase for the TCP in oropharyngeal carcinoma. Radiother Oncol. 2003 Mar;66(3):271-6. PMID: 12742266.

12.van Harten MC, Hoebers FJ, Kross KW, van Werkhoven ED, van den Brekel MW, van Dijk BA. Determinants of treatment waiting times for head and neck cancer in the Netherlands and their relation to survival. Oral Oncol. 2015 Mar;51(3):272-8. DOI: 10.1016/j.oraloncology.2014.12.003; PMID: 25541458.

13.Wan XC, Egloff AM, Johnson J. Histological assessment of cervical lymph node identifies patients with head and neck squamous cell carcinoma (HNSCC): who would benefit from chemoradiation after surgery? Laryngoscope. 2012 Dec;122(12):2712-2722. DOI: 10.1002/ lary.23572; PMID: 23060119; PMCID: PMC3522766.

14.Finn S, Toner M, Timon C. The node-negative neck: accuracy of clinical intraoperative lymph node assessment for metastatic disease in head and neck cancer. Laryngoscope. 2002 Apr;112(4):630-3. DOI: 10.1097/00005537-200204000-00007; PMID: 12150514.

15. Coskun HH, Medina JE, Robbins KT, Silver CE, Strojan P, Teymoortash A, et al. Current philosophy in the surgical management of neck metastases for head and neck squamous cell carcinoma. Head Neck. 2015 Jun; 37(6):915-26. DOI: 10.1002/hed.23689; PMID: 24623715; PMCID: PMC4991629. 